\title{
Are "Consistent Time Series Data Relating to Pakistan's Large-scale Manufacturing Industries" Inconsistent? Remarks to A.R. Kemal's Reply to a Comment
}

\section{Ole David Koht Norbye*}

In a comment [4] I discussed the methods used in two articles by A.R. Kemal $[1,2]$ which aimed at presenting new time series for the development of Pakistan's large scale manufacturing industries during the period 1959-1960 to 1969-1970. I found the methods questionable, and concluded that the new series probably were more misleading than the existing official statistics. To illustrate the weakness of the methodology I gave some numerical examples from Kemal's own material, and I also compared his figures with some data from other sources. In a reply to my comments [3] Kemal finds my observations either marginal or not well founded or even directly wrong. Since Kemal's reply in part builds on a misrepresentation of some of my comments and since his rejection of my objections on some points is not substantiated, I find it necessary to come back to this subject once more with some few remarks.

The main reason why $I$ want to repeat my warnings against the use of Kemal's figures is that his articles have the ambitious objective to produce a better set of figures than those which are available in official statistics and which would be accepted as a better alternative. Any social researcher has, of course, the right to manipulate existing statistics in order to obtain what he considers to be better and more reliable figures for his own analytical work. It is generally acknowledged that such manipulations may or may not lead to better data than the original ones. But as a rule it is only the manipulator himself who will use the data for his own purposes; if others want to use them, they do so because they consider them as the best available for their purposes, and they remain themselves responsible for this choice. Kemal's data, *The author is a Senior Research Fellow at the Chr. Michelsen Institute, DERAP, Ber-
gen, Norway. 
however, have been and are being used quite uncritically by a number of research workers inside the Pakistan Institute of Development Economics and perhaps also by others. My purpose is to warn against such uncritical use of Kemal's data.

Let me now turn to Kemal's summary of my objections.

\section{INVESTMENT DATA}

In response to my first objection that investment data based on CSO sample surveys are no better than CMI data, Kemal now states flatly that "in the survey there is no question of undercoverage as all firms are accounted for in stratified random sampling". But does not stratified random sampling depend on an adequate knowledge the number, size distribution etc. of all firms? Otherwise, how can one blow up the sample in a reliable manner?

Kemal accepts that his assumption, that 70 percent of the sanctioned investments is in full implemented, may not be valid, but maintains that a possible error would have very little impact and he seeks to show this by an example of a 10 percent error. This is not my point, however. The 70 percent rule of thumb may or may not be fairly correct on a global basis over a number of years, but errors in individual sectors in a single year can be far larger, easily up to 100 percent.

My third objection was based on Kemal's use of "investment indices" based on import of machinery up to 1962-1963, and direct data on investments for the later part of the period. Kemal asserts that there is no inconsistency, because the two series have been properly linked together. This misses my point that after all we have to do with two very different series which are not strictly comparable over time.

\section{DEPRECIATION RULES}

Kemal writes that "Mr. Norbye has expressed doubts regarding our assumptions of depreciation rates in (5)". This is a misunderstanding. His procedure is quite possibly sound enough. But what I doubt is whether the figures on fixed assets as presented by the firms that report to the CMI have been established in the manner in which Kemal has calculated them. I also added that data on fixed assets in manufacturing censuses in most countries are notoriously weak.

The crucial point in my comments, to which Kemal does not even refer, is the following: Kemal assumes that the ratios between fixed assets, as calculated by himself, and output, value added, industrial costs, employment and wages, other costs and indirect taxes are the same as in the CMI (for the years for which CMI is available). This will only hold true on two conditions:

that the CMI data for fixed assets are based on the same valuation of fixed investment and the same assumptions as regards depreciation as have been used by Kemal; and 
For more detailed observations see $[4 ;$ p. 101].

To sum up my observations on Kemal's procedures and estimates for investment and depreciation: In my opinion Kemal has not demonstrated, that his data on fixed investments give a reliable basis for estimates of fixed assets in different industries in single years. More seriously, he has not put forward any rational at all for his method of combining his own data with the ratios between fixed assets and with data on output, employment etc. as obtained from the CMI.

\section{PRICE INDICES}

The use of price indices is linked with Kemal's attempt in [2] to obtain data at constant prices. My point was that we cannot use the same price index to deflate gross output both at market prices and factor costs, and value added. He writes: "Mr. Norbye seems to be suggesting that if and only if the ratio of value added to output remains constant, one could use output price indices to deflate value added." I have never written anything which could be reasonably interpreted in this sense. I pointed out that if the ratio of value added to output changes, it may have two reasons: changes within the industry itself, and different price developments for output and inputs. I found it quite unnecessary to add that even if value added in relation to output at current prices remains constant over time, internal changes and relative price changes could have taken place, but fortuitously in such a manner that the resulting value added/gross output ratio did not change. Also in this case, of course, it would be of considerable interest from an analytical point of view to deflate inputs and output separately.

The use of the "double deflation method", which I recommend, is rejected by Kemal because "when applied to data, (it) yields such results as cast serious doubts on its usefulness". This is a new, and in itself valid and interesting argument, which Kemal did not use in his original article; there he simply stated that "because of the non-availability of price indices for al arge number of inputs" it was impossible to construct value added deflators. In his reply he now states flatly (on the basis of an article by P.A. David) that the "discussion of the Double Deflation Method and of deflation by output prices shows the theoretical superiority of the latter over the former". I am willing to accept that the simpler method is superior in practical terms, but the single index deflation method is only valid under very strict and unrealistic assumptions, which are far from being used in the data we are here discussing.

My point remains that since value added at "constant factor costs" rose from 22.8 percent to 28.2 percent of gross output in the course of a ten year period, we have reason to suspect that at least some of this increase may have been due to relative price changes between outputs and inputs. If this is so, the use of value added at "constant factor costs" obtained by deflating value added by the output price index only would exaggerate the growth of value
added over time.

Kemal writes that "Mr. Norbye has been very naive in saying that "for most industries it is no more difficult to construct some kind of price index for inputs than for outputs"." My remark was based on the fact that for most manufacturing industries in Pakistan available price indices for output are most 
unsatisfactory, and that if Kemal had been willing (or naive enough?) to accept

\section{FLUCTUATIONS OVER TIME}

In order to illustrate the weaknesses inherent in Kemal's method, I called attention to the very striking fluctuations over time which his new time series show. Kemal argues against my observations by misquoting me comcreases of mr. Norbye seems to have suggested that (a) there cannot be inyear to year except in percent in employment, output etc. in an industry from ployment, etc." [3, p. 113! . What (b) there cannot be fall in output, em-

"The employment figures as presented in the table, show unlikely large and sometimes very surprising jumps from one year to another. It is particularly disturbing that from time to time employment is shown to fall by 40 percent or more between two years. In some few cases for industries which employ relatively few people, the starting up of one large factory will, of course, lead to a sharp increase in employment, but such situations are few. Moreover, they do not explain the reported drastic falls in employment" [4, p. 104]. but I do find large abrupt declines in employment highly unlikely. Kemal, fluctuations actually can take place including some declines. He admits that more than 40 percent in and he can only show one case in which output fell by he uses are important in year (safety matches). The output indices which some cases, but the most violent to total output of a manufacturing sector in tries which represent only a small part of year fluctuations occur mostly in indusbelong. Upward jumps a small part of the manufacturing sector to which they drops from one year to not surprising, and in some cases fairly significant many of the figures from Kemer can be explained quite convincingly. But [4, table 1] behave in such an's series which I include in my comments see implausible.

Kemal fails to give satisfactory explanation of changes of a number of figures which he has undertaken between the publication of $[1,2]$. I agree
that he should make adjustments, when his figures are obviously meaningless,
but his footnote 5 in $[2$, p. 352] for two sectors.

\section{ABSOLUTE LEVELS OF EMPLOYMENT}

In my first comments I pointed out that Kemal's figures show that 400,000 additional jobs were created in large scale manufacturing between 1959-1960 and 1969-1970, against 110,000 according to CMI. He finds this comparison ludicrous, because, he maintains, the "value added at current factor cost from the national accounts exceeds by more than 66 percent the value added at factor cost obtained from the 1969-1970 CMI". If we do adjust the CMI 1969-1970 employment figure upwards by 66 percent, we obtain an increase in employment by 385,000 or very close to Kemal's figure. But on what basis has Kemal 
arrived at his adjusted national account figure? According to Kemal's first article [1] there was an adjusted undercoverage in terms of firms of 31.7 percent in 1967-1968 (data for later years were not available) against 8.4 percent in 1959-1960. Let us assume for the sake of agreement, that the undercoverage in terms of firms had grown to 40 percent in 1969-1970. But it certainly does not follow from this assumption that the undercoverage in terms of output, value added and employment was of the same order of magnitude. Moreover, the undercoverage in 1959-1960 must also be taken into account, what is apparently done neither in the national accounts, nor in Kemal's argument. In short, 1 do not find Kemal's argument on the employment subject convincing at all, neither methodologically nor numerically.

\section{PHYSICAL PRODUCTION DATA}

In my original comments I used available data on physical output of some goods as a basis for judging whether the production indices established by Kemal for various manufacturing sectors appeared to be realistic. Kemal comments, rightly so. that I did not take into account changes in quality or in the composition of output, but he makes no attempt to show how much influence such changes would have on the output figures. His objection may be qualitatively valid, but he has not offered any evidence of its quantitative importance.

\section{INDIRECT TAXES DATA}

Kemal points out that the figure which $I$ have quoted for indirect taxes in 1969-1970 is too low, and that therefore the difference between the indirect taxes as estimated bv Kemal and as reported in the public accounts is not so large as I have shown. I accept that the 1969-1970 figures as shown in my comments possibly may be too low, although I have no opportunity now to check the data. However, I am puzzled by Kemal's attempt to explain the remaining differences between his figures and those obtained from public accounts. I suggest that when CMI shows tax payments which apparently are not reflected in the public accounts the reason may be wrong classification of data by the reporting firms. Firms listed under one industry may in fact produce also goods similar to those of other industries which are subject to excise taxes; some apparent inconsistencies, therefore, may have ready explanations.

If, as is quite possible, my figures for indirect taxes are too low for 1969-1970, also my figures for 1965-1966 are too low see [4, table on p. 107]. We are still left, therefore, with the observation that whereas Kemal shows indirect taxes paid by large scale manufacturing firms to rise by 148.6 percent between 1965-1966 and 1969-1970, figures from public accounts show an increase of only about 90 percent. It is worthwhile looking further into these kinds of discrepancies before drawing conclusions from a statistical material.

\section{FINAL WORDS}

Nothing in what A.R. Kemal has written in his reply to my comments weakens significantly the strength of my arguments against the method used by Kemal. Nor does it change the fact that many of the figures which Kemal has arrived at appear very strange indeed. However, I readily admit that my 
attempts to compare Kemal's figures with other available information can be improved considerably; in fact, a major purpose of my comment was to urge that this be done before anybody makes any use of the results of Kemal's manipulations for statistical or analytical purposes.

I also believe that there is considerable scope for improving the CMI itself by going back to the original data and then tracing major missing firms for each year. Even if in most cases it would be impossible to collect new data from such firms, "gaps" could be filled by interpolation or extrapolation. For industries in which there is a large number of firms in important subsectors (such as the edible oil industry), a cruder approach would have to be used. But I am convinced that much better estimates can be done on the basis of the CMI itself.

I have never maintained that globally or over long periods Kemal's figures need be wildly wrong, although they may have a built in bias to become too high over time. But the year to year changes as shown by Kemal will necessarily be somewhat arbitrary as a result of the method used. This weakness makes them, in my opinion, quite unsuitable for detailed econometric research.

\section{REFERENCES}

1. Kemal, A.R. "Consistent Time Series Data Relating to Pakistan's Large-Scale Manufacturing Industries." The Pakistan Development Review. Vol. XV, No. 1. Spring 1976. pp. 28-63.

2. "Sectoral Growth Rates and Efficiency of Factor Use in Large-Scale Manufacturing Sector in West Pakistan." The Pakistan Development Review. Vol. XV, No. 4. Winter 1976. pp. 349-81.

3. ․ "Are "Consistent Time Series Data Relating to Pakistan's Large-Scale Manufacturing Industries:" Inconsistent? A Reply". The Pakistan Development Review. Vol. XVII, No. 1. Spring 1978. pp. 109-122.

4. Norbye, Ole David Koht. "Are "Consistent Time Series Data Relating to Pakistan's Large-Scale Manufacturing Industries" Inconsistent? A Comment." The Pakistan Development Review. Vol. XVII, No. 1. Spring 1978. pp. 99-108. 